\title{
Determining Disability: New Advances in Conceptualization and Research
}

\author{
Izabela Z. Schultz
}

Published online: 22 December 2009

(C) Springer Science+Business Media, LLC 2009

\begin{abstract}
This special issue of Psychological Injury and Law on disability presents state-of-the-art conceptualization and empirical research that will help psychologists and attorneys in the area of disability determination. This paper constitutes an introduction to and contextualization of the articles in the issue. It focuses on key advances in the field of disability research that are anticipated to move forward the practice of psychological injury and law. These new advances include the following: (1) a theoretical shift toward an integrative and dynamic biopsychosocial framework of health and disability, (2) development of complex multidimensional constructs of motivation, including primary, secondary, and tertiary gains and losses involved in disability claims, (3) increased emphasis on the perception of fairness and justice in disability claims from both psychological and legal perspectives, (4) increased understanding of the functional impact of psychological impairment, (5) inclusion of age-related factors in predicting disability, and (6) the interdisciplinary growth of this field.
\end{abstract}

Keywords Disability · Models · Biopsychosocial · Determination · Prediction · Function · Gains · Losses · Justice

\section{Why Focus on Disability in Psychological Injury and Law?}

Although disability prediction and determination constitute the key objectives of clinical and forensic assessments in

I. Z. Schultz $(\bowtie)$

University of British Columbia,

Room 297, 2125 Main Mall,

Vancouver, BC V6T 1Z4, Canada

e-mail: ischultz@telus.net psychological injury, they are still poorly understood (Schultz and Stewart 2008; Schultz 2008). There are no evidence-based practice guidelines in this field and limited access to graduate and postgraduate training as well. Historically, research in this discipline has been fragmented and guided by disparate conceptual frameworks and methodologies. Forensic psychologists providing disability testimony have been thus vulnerable in court.

The purpose of this special issue of the journal Psychological Injury and Law on the topic of disability is to introduce readers to a cross-section of the newest advances in the conceptualization of and research in occupational disability. The papers selected for this special issue are highly representative of the multifold theoretical and empirical developments that are bound to challenge, inform, and advance the field of psychological injury and law for years to come.

Theoretical and empirical advancements in the field of disability determination have been long overdue (Schultz 2008; Schultz and Stewart 2008). These developments have not yet been in keeping with the so-called "disability epidemic," i.e., growing statistics of temporary and permanent disability claims, particularly those involving complex and comorbid mental health disabilities (Gnam 2005), pain, and postconcussional sequelae.

The development of improved conceptual and evidentiary underpinnings for disability determination in psychological injury and law will assist forensic psychologists in applying the best practice standards and guidelines, as well as help treatment providers in dealing with disability issues. Furthermore, these advances will serve to inform litigation practices on both the defense and plaintiff side in the area of psychological disability and, from a long-term perspective, facilitate legislative and policy changes.

Conceptual and empirical developments in the area of psychosocial and vocational aspects of disability and 
disability determination are of critical importance to advance research and practice in psychological injury and the law. The accumulation of knowledge in diagnostically defined domains of inquiry, such as depression, posttraumatic stress disorder (PTSD), traumatic brain injury (TBI), and pain disorders, proceeds more rapidly than researcher and practitioner ability to integrate the new data, develop crossdiagnostic or transdiagnostic knowledge of disability, and improve clinical practices.

Practitioners in forensic psychology and neuropsychology, more often than in other applied specialties in psychology, are forced to answer complex, high-stakes clinical questions that require operating on the cutting edge of science. They are even pressured to move beyond the boundaries of science where empirical and evidentiary support is absent or where lack of clarity still reigns. Because of the high stakes involved in forensic assessments, being an expert witness in psychological injury cases means not only applying the best existing practices, but also continually striving to improve them based on the newest research advances.

There is no single source of knowledge on the newest advances that can inform the forensic practice of disability determination. Forensic psychologists and lawyers in the field draw from a vast and often disparate literature in clinical, rehabilitation, vocational and organizational health psychology, neuropsychology, physical medicine, occupational medicine, and disability-related law and policy, in addition to more clearly defined forensic psychological literature.

This special issue attempts to stimulate the integration of the seemingly disparate, yet connected, theoretical and research advances in the field of disability, showing how they can converge and translate into the improved practice of psychological injury and law.

Each paper accepted for this special issue represents a different lens contributing to improved understanding of the complexity and multidimensionality of the issues involved in disability determination. Recognition of such complexity and multidimensionality, although not always welcome in black and white legal decision-making contexts, likely constitutes the best way this field will continue to advance and mature.

\section{Toward an Integrative Concept of Disability}

In the last two decades, the field of disability, including psychological disability, has been evolving away from purely biomedical and forensic concepts of disability and toward the integration of both medical and social perspectives due to the advancement of the biopsychosocial model (Schultz 2008; Schultz and Stewart 2008; Schultz et al. 2007).
The paper by Peterson and Paul (2009) postulates that advances by the International Classification of Functioning Disability and Health (ICF), involving the World Health Organization's Model of Health and Disability (WHO 2001), constitute the most promising theoretical development not only for health scientists but also for practitioners in psychological injury and law. The major strengths of the ICF model include avoidance of diagnostic labels, a functional focus, and recognition of dynamic interactions between the individual and the context and environment in which one operates. Because these strengths that are inherent in the ICF model are also consistent with key objectives of disability determination in psychological injuries, the ICF model should be valued in work in the area.

Using the WHO framework, disability constitutes a contextualized "outcome or result of a complex relationship between an individual's health condition and personal factors, and the external factors that represent the circumstances in which the individual lives" (WHO 2001, p. 17). The review of the model by Peterson and Paul (2009) underscores that the ICF presents a dynamic, multifocal, and relational approach that integrates social and medical perspectives and lends itself to operationalization in social and health sciences.

Although, as Peterson and Paul (2009) point out, the application of the ICF model to disability determination in psychological injury and law is not a completed project, it is essential that psychologists adopt the lessons it offers. In particular, psychologists need to recognize the importance of assessing environmental demands and supports (e.g., in the workplace, the family, or the community) and their relationships with personal and health factors in producing limitations in activity and restrictions in participation that are disabling.

Determination of disability is not a static determination ending in a categorical conclusion of employability but rather a dynamic, reciprocal and temporal process evolving over time with changes in personal, health, and environmental factors. These factors need to be articulated in forensic disability determinations. Likewise, more research applications of the ICF model, already advanced in health and rehabilitation psychology, are postulated for forensic psychology, particularly in the absence of a competing integrative framework for research and practice and in the context of the growing accumulation of empirical evidence supporting the ICF model.

\section{Beyond Malingering Detection: The Economy of Gains and Losses in Disability}

Motivational and coping factors are postulated to mediate between impairment and disability (Roessler 1989; Schultz 
and Brady 2003), yet in forensic psychology practice and research, they are often denigrated as equivalent to suboptimal effort and equated with secondary gain, malingering, symptom magnification, and symptom invalidity. Coping factors, processes, and outcomes, such as passive or avoidant coping and catastrophizing, have been considered significant predictors of disability (e.g., Dunn and Dougherty 2005; Elliott et al. 2005; Heinemann 1995; Johnson et al. 2006; Schultz and Stewart 2008; Wegener and Shertzer 2006), but they are not routinely identified in psychological disability determinations.

In forensic neuropsychological assessments, determination of assessment validity and effort in testing has become a standard of practice (Rohling and Boone 2007). Although formal evaluations of effort in testing and symptom validity ought to constitute essential components of all assessments, they are at times erroneously considered narrowly to be a proxy for malingering detection in disability evaluations. Historically, the concept of "secondary gain" has become one of the core yet most commonly misinterpreted constructs in the forensic model of disability (Aronoff 1991; Kennedy 1946; Mendelson 1994; Schultz et al. 2000). The misinterpretation of "secondary gain" has been detrimental to the development of other motivational constructs involving gains and losses associated with disability that have a potential to more comprehensively and accurately explain the relationship between impairment and disability (Dersh et al. 2005; Fishbain et al. 1994; Kwan et al. 2001; Leeman et al. 2000).

As explained in the paper by Worzer et al. (2009), although secondary gains may in fact perpetuate disability, secondary losses associated with disability are often more powerful psychological factors. The authors utilize literature on chronic pain to illustrate how individuals with pain progress to disability by way of motivational factors associated with primary, secondary, and tertiary gains and losses (the latter including physical functioning and independence, social relationships, employment and familial roles, financial stability, self-esteem, and general world view). The authors discuss gaps in the psychological literature that have resulted in poor understanding of motivation underlying disability and illness behaviors and, among them, one finds the economy of or balance among gains and losses.

The conceptual framework for understanding the balance of gains and losses presented in this paper can open and expand a scientific and clinical discussion on how individuals position themselves on the continuum of gains and losses and how this process changes over time and in different contexts while in transition to or away from disability. Further research on the validity and utility of the proposed model is needed. In the meantime, psychological disability evaluation has the opportunity to move beyond the anachronistic dualistic model of human motivation in disability as focusing on either gains or lack thereof. Assessment of motivational factors in disability determination will likely need to be augmented by recognition of complexity, multidimensionality, temporal dimensions, and the interactivity of motivational constructs underlying disability, such as those identified in the paper by Worzer et al. (2009).

\section{Fairness and Justice Issues in Disability Claims: Psychological and Legal Perspectives}

The simplistic forensic focus on individual psychopathology as a source of perpetuation of disability is being gradually replaced or supplemented by a more systemic perspective that examines the relationship of the injured party to the administrators and professionals involved in decision making about claims and to other contextual factors, such as an employer's offer of return to work accommodations. In this regard, this special issue presents leaders in the field contributing to the new research focus on the system-related dimension of perception of justice and fairness in disability claims.

It is not surprising that improved understanding of the economy of gains and losses in disability development leads to investigation of psychological and legal themes related to perceived fairness and justice of the compensation system and process as powerful factors in the formation and maintenance of disability. Three papers published in this present issue deal directly with these themes; there are two empirical papers on the topic and one legal paper. First, Franche et al. (2009) present research on the development of an assessment tool of perceived injustice and the relationship of scores obtained with the instrument to heightened pain behavior and disability. Second, Sullivan et al. (2009) undertook empirical investigation of the pain elicited by putting forth effort on physical tasks and scores on a different scale of perceived injustice. Third, in a legal paper, Hayman (2009) explores jurisprudence and emerging legal issues related to damages for mental distress and bad faith in disability claims. The three papers have overarching conceptual themes and their unique contributions to the field are discussed further below.

Factors associated with perceived justice of the compensation process from the individual claimant's perspective have been rarely investigated, although experiences involving mistrust and suspiciousness, disrespect, lack of validation of harm by the injury, gender bias, and difficulty navigating the compensation system, as stipulated in the paper of Franche et al. (2009), have been described in the literature. The authors report on the development and validation of a measure of the perceived justice of the compensation process that builds on four theoretical 
dimensions of justice: distributive, procedural, informational, and interpersonal. With further validation research in other jurisdictions and with different populations, such a measure could become incorporated in disability determinations. In the Franche et al. (2009) study, the concurrent validity of the scale is supported by relationships of distributive and procedural justice with claim status, claim processing delay, perception of going back to work too soon, and duration and dissatisfaction with work accommodations.

The study by Sullivan et al. (2009) uses a different measure of perceived justice and reveals that individuals with elevated levels of perceived injustice displayed more protective pain behaviors than individuals with low levels of perceived injustice, regardless of physical task demands. Like Franche et al. (2009), the authors of this study postulate the importance of evaluating perceived injustice as one of the key predictors of disability and potential targets for interventions.

From a legal perspective, the paper by Hayman (2009) examines the evolution of law in relation to the willingness to recognize the importance of intangible loss, often associated with mental distress arising from breach of contract between the disability insurer and the claimant where the claimant has been wrongly denied benefits. Hayman's (2009) article aptly illustrates that the area of psychological injury and law has much to learn from attorneys and that third parties acting in bad faith complicate the complainant's psychological outcome after events at claim.

These three papers relate to issues of justice in the compensation process, highlighting the need to incorporate improved understanding of the relationship between disability and perceived justice of the process of disability determination, especially in cases of psychological injury. Likewise, legal professionals are encouraged to pay attention to (and ask psychologists to evaluate) the intangible psychosocial issues associated with any breach of contract between the disability insurer and the claimant.

\section{Understanding the Functional Impact of Psychological Impairment}

Consistent with the proliferation of the WHO's (2001) model of disability, the emphasis on a cross-diagnostic and functional approach in clinical and rehabilitation research and practice has been growing. The complex relationship between psychological and neuropsychological diagnoses and their functional impacts, including in work, education, relationships, daily living and recreational functioning, and health care utilization, has been poorly understood and generally understudied, especially in psychology.
In psychological injury determinations, the evaluation of functional impact has often been relegated to occupational therapists and vocational rehabilitation evaluators. Yet, forensic psychologists are frequently charged with the responsibility for disability determination and they often have key clinical evidence to support such determinations. Reasons for the area being understudied are multifold, including (a) psychologists' historic focus on diagnosis and pathology rather than on function; (b) lack of appropriate taxonomies and conceptualizations of functional impairment; (c) confusion around the relationship between impairment and disability; (d) the absence of a contextual/environmental focus (to complement the focus on individuals) in forensic psychological practice; and (e) the limited supply of psychometrically sound tools for the evaluation of functional impairment (beyond behavioral scales used in working with children and persons with severe disability-related barriers) in ecologically focused assessments (Halpern and Fuhrer 1984; Shriver et al. 2001; Yoman and Edelstein 1994).

As Wald and Taylor (2009) point out in their paper, evidence of functional impairment, in this case in PTSD, is important in order to be able to render scientifically informed expert opinions on prognoses and disability. In their literature review, Wald and Taylor present an integration of the current, often fragmented, literature in the field of PTSD. As noted in the article, the development and validation of the Work Limitations Questionnaire (Lerner et al. 2001) has sparked a series of studies on the occupational impact of mental health disorders, including PTSD. Results of this well-validated questionnaire can inform not only disability determinations but also guide development and implementation of job accommodations that directly address identified functional limitations.

Further work on the functional aspects of diagnoses other than PTSD, and especially depression and brain injury, has been underway and is reaching a level of evidence accumulation that is appropriate for knowledge translation to forensic practice (Schultz and Rogers 2009). As pointed out, however, by Wald and Taylor (2009), longitudinal studies in this emerging field are lacking.

\section{Complex Predictive Modeling of Disability: Age and Longitudinal Factors}

Empirically based (also called "actuarial") multivariate formulae predicting disability from early clinical markers have been developing rapidly in the field of musculoskeletal pain, reaching predictive accuracy of about $80 \%$ for return to work outcomes (Burton et al. 2003; Linton et al. 2005; Schultz et al. 2005; Schultz and Gatchel 2005), especially in back pain conditions. Although advances have 
been made toward the development of predictive models in TBI, whiplash, PTSD, and other injury-related conditions, research in this field continues to be a "work in progress" due to methodological challenges (Linton et al. 2005; Schultz et al. 2005), including (a) problems with small sample sizes, (b) use of samples of convenience, (c) difficulty defining and measuring predictors and outcomes, (d) shortage of well-designed longitudinal studies, (e) insufficient appreciation of temporal factors in the disablement process, and $(\mathrm{g})$ problems with generalization of findings to other settings, populations, and jurisdictions. Yet, development and validation of empirically supported multivariate models of prediction of disability will greatly assist in the transition of forensic prognostication from a judgment-based (and thus potentially biased) exercise to evidence-informed decision making and disability determination (Linton et al. 2005; Schultz and Gatchel 2005).

The study by Hirsh and colleagues (2009) in this special issue represents an attempt to capture some of the key predictors of employment outcomes in spinal cord injury (SCI), including demographic, psychological, and physical factors. The results of the study indicate that chronological age and age at SCI onset are significant predictors of employment status.

Understanding the impact of chronological age, age at injury onset, and the longitudinal course of disability, in addition to psychological factors identified as predictors of disability, is critical for rendering evidence-based expert opinions on functional outcomes such as employment. In the case of major neurological and psychological trauma, such as SCI, the importance of age-related predictors cannot be underscored enough in forensic disability determinations. The study by Hirsh et al. (2009) illustrates the type of quantitative methodology and research findings forensic psychologists need to draw from in their research and practice. Moreover, it illustrates that there is no "one size fits all" universal formula and that variables such as age, gender, minority status, and cultural background need empirical support in relation to critical issues in disability determinations and to primary assessment instruments in the area of psychological injury and law.

\section{Toward the Future: Interdisciplinarity}

As illustrated in this special issue, in the field of disability determination, current forensic research approaches and practices cannot be confined to traditional specialties in psychology, such as clinical, neuropsychology, and rehabilitation psychology. Future advances in psychological disability determination will likely depend on the forensic psychologist's ability to draw from "nontraditional" psychology literature, including counseling, health, communi- ty, and organizational psychology, and from fellow health disciplines (including occupational service and therapy, occupational and rehabilitation medicine, nursing, and vocational rehabilitation).

Moreover, the future of disability determination and clinical and employment interventions in psychological injury cases will require an interdisciplinary or perhaps a transdisciplinary approach to match the evolving biopsychosocial model and meet the challenge of evidence-based practice. When called to court, psychologists in the area need to be keenly aware of how their recommendations and interventions have promoted a return to work and mitigated losses related to disability and the degree to which the physical and psychological injuries sustained by their patients might impede a full return to work according to the literature. The articles in this special issue reinforce the knowledge set needed to answer questions such as these. Moreover, they provide attorneys with the evidence base that psychologists use or should be using in their current and future work in the area.

\section{References}

Aronoff, G. M. (1991). Chronic pain and the disability epidemic. Clinical Journal of Pain, 7, 330-338.

Burton, G., Waddell, A. K., \& Main, C. (2003). Screening to identify people at risk of long-term incapacity for work: A conceptual and scientific review. London: Royal Society of Medicine Press.

Dersh, J., Polatin, P., Leeman, G., \& Gatchel, R. (2005). Secondary gains and losses in the medicolegal setting. In I. Z. Schultz \& R. J. Gatchel (Eds.), Handbook of complex occupational disability claims: Early risk identification, intervention, and prevention (pp. 421-442). New York: Springer.

Dunn, D. S., \& Dougherty, S. B. (2005). Prospects for a positive psychology of rehabilitation. Rehabilitation Psychology, 50(3), 305-311.

Elliott, T. R., Kurylo, M., \& Rivera, P. (2005). Positive growth following acquired physical disability. In C. R. Snyder \& S. J. Lopez (Eds.), Handbook of positive psychology (pp. 687-699). New York: Oxford University Press.

Fishbain, D. A., Cutler, R. B., Rosomoff, R. S., \& Rosomoff, H. L. (1994). The problem-oriented psychiatric examination of the chronic pain patient and its application to the litigation consultation. Clinical Journal of Pain, 10(1), 28-51.

Franche, R.-L., Severin, C. N., Lee, H., Hogg-Johnson, S. H., Hepburn, C. G., Vidmar, M., et al. (2009). Perceived justice of compensation process for return-to-work: Development and validation of a scale. Psychological Injury and Law, this issue

Gnam, W. H. (2005). The prediction of occupational disability related to depressive and anxiety disorders. In I. Z. Schultz \& R. J. Gatchel (Eds.), Handbook of complex occupational disability claims: Early risk identification, intervention, and prevention (pp. 371-384). New York: Springer.

Halpern, A. S., \& Fuhrer, M. J. (1984). Functional assessment in rehabilitation. Baltimore: Paul H. Brooks.

Hayman, F. E. (2009). Damages for mental distress and bad faith in disability claims. Psychological Injury and Law, this issue

Heinemann, A. W. (1995). Measures of coping and reaction to disability. In L. A. Cushman \& M. Scherer (Eds.), Psychological 
assessment in medical rehabilitation (pp. 39-90). Washington: American Psychological Association.

Hirsh, A. T., Molton, I. R., Johnson, K. L., Bombardier, C. H., \& Jensen, M. P. (2009). The relationship of chronological age, age at injury, and duration of injury to employment status in individuals with spinal cord injury. Psychological Injury and Law, this issue

Johnson, L. M., Zautra, A. J., \& Davis, M. C. (2006). The role of illness uncertainty on coping with fibromyalgia symptoms. Health Psychology, 25(6), 696-703.

Kennedy, F. (1946). The mind of the injured worker: Its effect on disability. Compensation Medicine, 1, 19-24.

Kwan, O., Ferrari, R., \& Friel, J. (2001). Tertiary gain and disability syndromes. Medical Hypotheses, 57, 459-464.

Leeman, G., Polatin, P., Gatchel, R., \& Kishino, N. (2000). Managing secondary gain in patients with pain-associated disability: A clinical perspective. Journal of Workers Compensation, 9, 25-44.

Lerner, D., Amick, B., Rogers, W. H., Malspeis, S., Bungay, K., \& Cynn, D. (2001). The Work Limitations Questionnaire. Medical Care, 39, 72-85.

Linton, S. J., Gross, D., Schultz, I. Z., Main, C. J., Côté, P., Pransky, G., et al. (2005). Prognosis and the identification of workers risking disability: Research issues and directions for future research. Journal of Occupational Rehabilitation, 15(4), 459474.

Mendelson, G. (1994). Chronic pain and compensation issues. In P. D. Wall \& R. Melzack (Eds.), Textbook of pain (3rd ed., pp. 13871400). New York: Churchill Livingstone.

Peterson, D., \& Paul, H. (2009). Using the international classification of functioning, disability \& health (ICF) to conceptualize disability and functioning in psychological injury and law. Psychological Injury and Law, this issue

Rohling, M. L., \& Boone, K. B. (2007). Future directions in effort assessment. In K. B. Boone (Ed.), Assessment of feigned cognitive impairment: A neuropsychological perspective (pp. 453-469). New York: Guilford.

Roessler, R. T. (1989). Motivational factors influencing return to work. Journal of Applied Rehabilitation Counseling, 20, 14-17.

Schultz, I. Z. (2008). Disentangling the disability quagmire in psychological injury: Part 1-Disability and return to work: Theories, methods, and applications. Psychological Injury and Law, 1, 94-102.

Schultz, I. Z. \& Brady, D. O. (2003). Psychological injuries at trial. Chicago: American Bar Association.

Schultz, I. Z., \& Gatchel, R. J. (2005). Research and practice directions in risk for disability prediction and early intervention. In I. Z. Schultz \& R. J. Gatchel (Eds.), Handbook of complex occupational disability claims: Early risk identification, intervention, and prevention (pp. 523-540). New York: Springer.

Schultz, I. Z., \& Rogers, E. S. (Eds.) (2009). Handbook of job accommodations in mental health. New York: Springer. In press.

Schultz, I. Z., \& Stewart, A. M. (2008). Disentangling the disability quagmire in psychological injury and law: Part 2-Evolution of disability models: Conceptual, methodological and forensic practice issues. Psychological Injury and Law, 1, 103-121.

Schultz, I. Z., Crook, J., Fraser, K., \& Joy, P. W. (2000). Models of diagnosis and rehabilitation in musculoskeletal pain-related occupational disability. Journal of Occupational Rehabilitation, 10, 271-293.

Schultz, I. Z., Crook, J., Berkowitz, J., Milner, R., \& Meloche, G. R. (2005). Predicting return to work after low back pain injury using the psychosocial risk for occupational disability instrument: A validation study. Journal of Occupational Rehabilitation, 15(3), 365-376.

Schultz, I. Z., Stowell, A. W., Feuerstein, M., \& Gatchel, R. J. (2007). Models of return to work for musculoskeletal disorders. Journal of Occupational Rehabilitation, 17, 327-352.

Shriver, M. D., Anderson, C. M., \& Proctor, B. (2001). Evaluating the validity of functional behavior assessment. School Psychology Review, 30(2), 180-192.

Sullivan, M. J. L., Davidson, N., Garfinkel, B., Siriapaipant, N., \& Scott, W. (2009). Perceived injustice is associated with heightened pain behavior and disability in individuals with whiplash injuries. Psychological Injury and Law, this issue

Wald, J., \& Taylor, S. (2009). Work impairment and disability in posttraumatic stress disorder: A review and recommendations for psychological injury research and practice. Psychological Injury and Law, this issue

Wegener, S. T., \& Shertzer, E. L. (2006). Foundations of rehabilitation psychology: Adaptation and emotion. American Psychological Symposium \#3134, American Psychological Association Annual Convention, New Orleans, 12 August, Department of Physical Medicine and Rehabilitation, Johns Hopkins University School of Medicine.

World Health Organization (WHO). (2001). International classification of functioning, disabilities and health problems. Geneva: World Health Organization (WHO).

Whitney E., Worzer, W. E., Kishino, N. D., \& Gatchel, R. J. (2009). Primary, secondary, and tertiary losses in chronic pain patients. Psychological Injury and Law, this issue

Yoman, J., \& Edelstein, B. A. (1994). Functional assessment in psychiatric disability. In J. R. Bedell (Ed.), Psychological assessment and treatment of persons with severe mental disorders (pp. 31-56). Washington: Taylor \& Francis. 